doi:10.1017/\$1041610219000474

\section{Science media - the best way to reach the target audience for a pre-clinical AD study}

All researchers understand the frustrations of clinical trial recruitment. Pre-generated databases are currently fashionable as a tool, especially for preclinical Alzheimer's disease (AD) studies, but little is known of their effectiveness (Grill et al., 2018). When recruiting for the Australian cohort of the Anti-Amyloid Treatment in Asymptomatic Alzheimer's disease study (The A4 Study), we found that a pre-generated database was indeed useful. Also, that continued building of the database was assisted through promotion via science media.

We aimed to recruit 100 eligible participants and began by combing the pre-generated Florey BrainPET database-the result of previous, selfenrollment media drives. We sent invitations to people whose demographics and medical/treatment responses met study criteria $(N=215)$.

We found that this database, dedicated to capturing people interested in brain research, was valuable for recruitment. Only $10 \%$ of BrainPET registrants underwent Visit 1 screening, yet formed $25 \%(N=25)$ of our final cohort. Although not a pre-characterized sample (recommended by Boada et al., 2018), the database contained enough information to identify people at risk (Pillai and Cummings, 2013) and exclude others. It is unusual for one site to contribute such a large portion of the overall cohort in a multicenter trial. Had we been looking for a smaller group, the database alone would probably have been sufficient.

As we exhausted this database, we presented $\mathrm{AD}$, PET imaging, and/or the A4 study on various television and radio news and current affairs programs $(N=9)$. People were directed to a study specific database or telephone number. A call center was employed to deal with an expected high volume of responders.

We found science media the most rewarding. The Catalyst science program was the best recruiter with $43 \%$ of eligible responders undergoing screening. The brief paragraphs in the University of Melbourne newsletters and a flyer placed in Dementia Australia's quarterly magazine provided small numbers, but cumulatively, $42 \%$ underwent screening. Word-of-mouth meetings of like-minded people also yielded $42 \%(N=64)$. Reaching the target audience for clinical trial recruitment is always the challenge. It would seem that the BrainPET advertising, Catalyst science program, university newsletters, and word of mouth were the means by which to reach individuals interested in $\mathrm{AD}$ research, cognizant of the underlying issues.

Other strategies generated a significant initial response that did not translate to actual screening visits to such a degree. Following initial interest, finding out about study commitment saw many withdraw interest. Results are listed in Table 1.

The call center was not beneficial. A random sample of responders was telephoned with mixed results, and all had to be recontacted to ensure that those eligible were included.

Self-enrollment via the internet was efficient, as it reduced costs and time needed for data entry. It also enabled bulk BCC emails to be sent to ineligible participants and efficient growth of the database for future studies through affirmative replies.

In summary, recruitment to secondary prevention studies is indeed assisted by using a targeted database. Self-enrollment via the internet reduces costs, and rebuilding the database is best assisted by advertising through science-focused media.

\section{Conflict of interest}

None.

\section{Description of authors' roles}

M. Mastwyk designed the study, supervised data collection and analysis, and wrote the paper.

A. Barac collected the data, completed analysis, and reviewed the paper.

Morgan Radler collected the data and reviewed the paper.

Rebecca Sgambellone collected the data and reviewed the paper.

Vasantha Pather Lowen collected the data and reviewed the paper.

Natasha Mitchell collected the data and reviewed the paper.

George Zisis collected the data and reviewed the paper.

Christopher Cleon Rowe generated the preexisting database and reviewed the paper.

Colin Louis Masters supervised the study and reviewed the paper. 
Table 1. Participant recruitment by publicity source

\begin{tabular}{|c|c|c|c|c|c|c|c|c|c|}
\hline DATE & SOURCE & $\begin{array}{l}\text { MEAN } \\
\text { AGE }\end{array}$ & $\begin{array}{l}\text { MALE } \\
(\%)\end{array}$ & RESPONSES & ELIGIBLE & DECLINED & $\begin{array}{c}\text { SCREENED } \\
(\%)\end{array}$ & SCANNED & $\begin{array}{c}\text { PET } \\
\text { Positive }\end{array}$ \\
\hline Pre-Sep 2014 & $\begin{array}{l}\text { BrainPET } \\
\qquad(N=942)\end{array}$ & 66.5 & 42.7 & 942 & 215 & 117 & $98(45.6 \%)$ & 69 & 25 \\
\hline 01 Dec 14 & ${ }^{\star}$ Channel 7 News & 67.3 & 42.6 & 209 & 89 & 63 & $26(29.2 \%)$ & 11 & 4 \\
\hline 17 Mar 15 & $\begin{array}{l}{ }^{\star} \text { Catalyst } \\
\text { (science program) }\end{array}$ & 68.9 & 44.4 & 567 & 310 & 177 & $133(42.9 \%)$ & 88 & 19 \\
\hline 27 Sep 15 & $\begin{array}{l}{ }^{\star} \text { Red Symons } \\
\quad \text { (breakfast radio) }\end{array}$ & 67.1 & 47.9 & 140 & 39 & 25 & $14(35.9 \%)$ & 10 & 1 \\
\hline 31 Oct 15 & ${ }^{\star}$ A Current Affair & 67.8 & 28.2 & 39 & 26 & 20 & $6(23.1 \%)$ & 1 & 0 \\
\hline 29 Apr 16 & $\begin{array}{c}{ }^{\star} \text { Herald Sun } \\
\text { editorial }\end{array}$ & 70.4 & 49.0 & 502 & 335 & 234 & $101(30.1 \%)$ & 60 & 12 \\
\hline 28 Apr 16 & $\begin{array}{l}\text { *774 (morning } \\
\text { radio) }\end{array}$ & 70.0 & 46.7 & 167 & 124 & 90 & $34(27.4 \%)$ & 24 & 4 \\
\hline 28 Apr 16 & $\begin{array}{l}\text { 3AW (morning } \\
\text { radio) }\end{array}$ & 66.7 & 49.0 & 51 & 25 & 18 & $7(28.0 \%)$ & 6 & 1 \\
\hline $\begin{array}{c}\text { Mar-Sep } \\
2016\end{array}$ & $\begin{array}{l}\text { Brain Matters U3A, } \\
{ }^{\star} \text { Memory } \\
\text { Matters, } \\
\text { UniMelb eNews }\end{array}$ & 71.4 & 38.0 & 137 & 88 & 51 & $37(42.0 \%)$ & 27 & 6 \\
\hline $21 \mathrm{Jul} 16$ & ${ }^{\star}$ The Age & 60.6 & 39.5 & 147 & 54 & 40 & $14(25.9 \%)$ & 9 & 2 \\
\hline 21 Sep 16 & ${ }^{\star} 7: 30$ Report & 65.8 & 53.7 & 134 & 58 & 51 & $7(12.1 \%)$ & 7 & 2 \\
\hline \multirow[t]{9}{*}{ 02 Jun 17} & The Conversation & 63.1 & 50.0 & 22 & 3 & 3 & $0(00.0 \%)$ & 0 & 0 \\
\hline & Word of mouth & 67.3 & 32.5 & 268 & 151 & 87 & $64(42.4 \%)$ & 36 & 8 \\
\hline & Specialist referrals & 71.0 & 49.0 & 49 & 35 & 14 & $21(60.0 \%)$ & 11 & 2 \\
\hline & "The paper" & 64.7 & 43.4 & 83 & 37 & 24 & $13(35.1 \%)$ & 7 & 3 \\
\hline & "Radio" & 66.8 & 39.9 & 228 & 112 & 66 & $46(41.1 \%)$ & 35 & 5 \\
\hline & "Television" & 64.2 & 38.6 & 70 & 26 & 19 & $7(26.9 \%)$ & 5 & 2 \\
\hline & “Internet” & 62.9 & 45.5 & 123 & 39 & 31 & $8(20.5 \%)$ & 6 & 1 \\
\hline & Don't remember & 68.1 & 47.7 & 279 & 139 & 112 & $27(19.4 \%)$ & 17 & 5 \\
\hline & Totals & 67.5 & 43.7 & 4157 & 1905 & 1242 & 663 & 429 & 102 \\
\hline
\end{tabular}

^Site-initiated promotion

\section{Acknowledgments}

The authors would like to thank Reisa Sperling of Harvard Medical School, Boston, MA, USA; the A4 study team at the Alzheimer's Therapeutic Research Institute, University of Southern California, San Diego, CA, USA; and Eli Lilly and Company, Indianapolis, IN, USA.

\section{References}

Boada, M. et al. (2018). Patient engagement: the fundacío ACE framework for improving recruitment and retention in Alzheimer's disease research. Fournal of Alzheimer's Disease, 62, 1079-1090. doi: 10.3233/JAD-170866.

Grill, J. D. et al. (2018). Constructing a local potential participant registry to improve Alzheimer's disease clinical research recruitment. Fournal of Alzheimer's Disease, 63, 1055-1063. doi: 10.3233/JAD-180069.

Pillai, J. A. and Cummings, J. L. (2013). Clinical trials in predementia stages of Alzheimer's disease. Medical Clinics of NorthAmerica, 97, 439-457. doi: 10.1016/j.mcna.2013.01.002.
Maree Mastwyk, ${ }^{1}$ Alex M. Barac, ${ }^{2}$

Morgan Radler, ${ }^{3}$ Rebecca Sgambellone, ${ }^{4}$ Vasantha Pather Lowen, ${ }^{4}$ Natasha Mitchell, ${ }^{2}$ George Zisis, ${ }^{2}$ Christopher Cleon Rowe ${ }^{5,6}$ AND COLIN LOUIS MASTERs ${ }^{2}$

${ }^{1}$ Monash Aged Psychiatry Research Centre, Caulfield Hospital, Caulfield, VIC, Australia

${ }^{2}$ Florey Institute of Neuroscience and Mental Health, Parkville, VIC, Australia

${ }^{3}$ Cognitive Dementia and Memory Service, Wantirna, VIC, Australia

${ }^{4}$ Formerly of the Florey Institute of Neuroscience and Mental Health, Parkville, VIC, Australia

${ }^{5}$ Molecular Imaging Research, Austin Health, Heidelberg, VIC, Australia

${ }^{6}$ University of Melbourne, Parkville, VIC, Australia

Correspondence should be addressed to: Maree Mastwyk, Monash Aged Psychiatry Research Centre, Caulfield Hospital, 260 Kooyong Rd., Caulfield, VIC 3162, Australia. Email: m.mastwyk@alfred.org.au 